\title{
A Review of the Techniques and Guidelines in Adult Autopsies Anu Sasidharan ${ }^{1 *}$, Nadia M. Al-Kandary ${ }^{2}$ \\ ${ }^{1}$ Associate Professor \& Unit Head of Forensic Pathology, Department of Forensic Medicine \& Toxicology, Amrita School of Medicine, Amrita Vishwa Vidyapeetham, Kochi, Kerala, India \\ ${ }^{2}$ Head of Forensic Pathology Section, Forensic Medicine Department, General Department of Criminal Evidence, Kuwait
}

DOI: $10.36348 /$ sjm.2019.v04i12.006

| Received: 18.12.2019 | Accepted: 25.12.2019 | Published: 26.12.2019

*Corresponding author: Dr. Anu Sasidharan

\section{Abstract}

A medico-legal autopsy on an adult if performed completely and systematically, with a reasonable uniformity and clarity can help in the betterment of outcomes while providing justice. The pre-requisites prior to an autopsy, and a thorough external examination are very important before moving on with the internal examination. In many situations a proper external examination will be sufficient to give a medico-legal report; if done methodically. There are four types of skin incisions employed in a medico-legal autopsy to examine three body cavities. The internal examination can be done using four dissection techniques as outlined in the existing literature. Examination of brain, heart, neck structures, spinal column and genitalia are very important and requires an organized approach in order to not to miss salient findings. Finally, while closure of the cadaver the doctors must bear a very important fact in mind that the body on the table was once housed by a living being and hence s/he must be treated with the same respect and dignity as one would expect him/herself to be treated by others.

Keywords: Medico-legal Autopsy, I- shaped Incision, Letulle's En Masse Dissection, Ghon's En Bloc Dissection, Virchow's Dissection, Rokitansky's Dissection.

Copyright @ 2019: This is an open-access article distributed under the terms of the Creative Commons Attribution license which permits unrestricted use, distribution, and reproduction in any medium for non-commercial use (NonCommercial, or CC-BY-NC) provided the original author and source are credited.

\section{INTRODUCTION}

A medico-legal autopsy should be performed systematically and completely. There is nothing as bad as doing a partial autopsy or an incomplete autopsy when a medico-legal work is considered. In spite of all recent advancements such as virtopsy, the basic or times immemorial dissection procedures have not yet left the dias. Perhaps, no modern technique or approach can replace the conventional dissection techniques. A prosector in order to successfully perform such conventional procedures requires a basic knowledge of anatomical architecture and pathological changes in a human body. Ensuring a uniformity and clarity of the various procedures and techniques will help in the betterment of the outcome of such medico-legal autopsies.

Autopsy procedures help to identify any inconsistencies between clinical and post-mortem diagnosis. A surgery when done by a doctor is often met with pain/suffering by the patient and definitely with benefit for the patient; whilst an autopsy when done by a doctor is never met with pain/suffering by the cadaver (with mental trauma/pain for the doctor and suffering for the next of kin), but for justice to the dead and for benefit of the living individuals and judiciary. Approximately $10 \%$ of autopsy findings have revealed to be beneficial in significantly changing clinical management of patients [1]. Mortality data not verified by a post-mortem examination must be viewed with caution. Things have come to such an extent that autopsies are actually necessary to ensure the accuracy of death certificates. Hence with regards to autopsy procedures; there must be an acceptable practice while it will be acknowledged that this may not always be exactly the same as best practice.

\section{Checklist prior to starting autopsy:}

- Go through the requisition form provided by the magistrate / police

- Accumulate and assess all the available clinical information

- Check the identity of the deceased

- If there are any clarifications required; ask them to the appropriate person

- Request the presence of one more expert, even if it's from clinical specialty for expert guidance

- Police officer or someone on his behalf can be permitted to witness the autopsy procedures provided it can speed up investigation 
- Identify the main areas of interest in the medicolegal case and accordingly plan the autopsy procedures that are required in the case (including special techniques)

- Wear proper garb and assess any risks or hazards for each case

- If samples are required to be taken for ancillary investigations; keep the necessary containers ready prior to starting the dissection procedures

- Keep the autopsy area clean

\section{General external examination:}

All the observations and findings need to be recorded in the detailed notes of the prosector in a simple language. S/he can take the help of another person while examining the body. Take the length and weight of the cadaver. Depending upon the length of the cadaver, position the cadaver properly on the dissection table adjusting the shoulder and buttocks supports (Fig. 1). If the prosector is right-handed, then s/he should stand on the right side of the dissection table. Inspect the body from head to toe and palpate if needed. Do not miss to examine the entire back aspect of the body. Often most of the unseen as well as important findings are on the back aspect of the torso. Even the investigating officers at time do fail to notice important findings at this region especially if they are faint / small to be remarked.

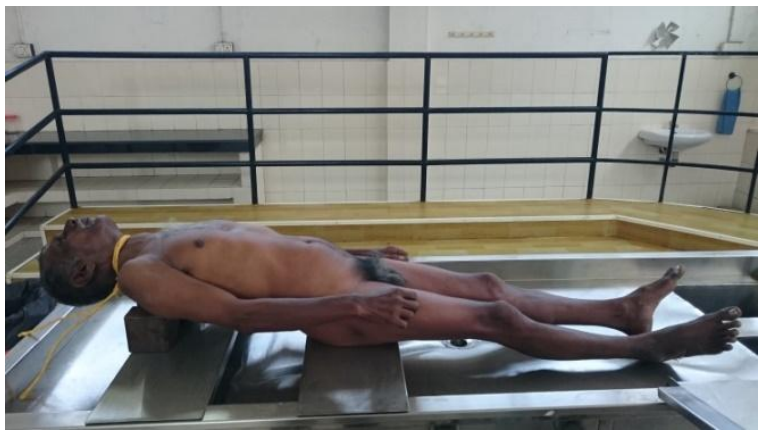

Fig-1: Positioning of the Cadaver

There are three areas to be not forgotten to be palpated; namely the scalp region for bony deformities (better felt than seen), the hyper mobility of neck region (to rule out cervical bone fractures) and the fracture deformity of any other part of the body. Examine all the body orifices and also the iatrogenic injuries if any present on the body. The nature of such ante mortem / per mortem injuries must be correlated with the treatment records obtained by the police officers. In the absence of such records; it must be insisted to be submitted to the prosector if possible before completing external examination or at least before handling over the body to the relatives. In the latter, the entire body can be washed and re-inspected for any changes in the above noted findings. Post-mortem changes need to be assessed next. This includes rigor mortis, post-mortem staining, signs of decomposition etc. Maggots / larvae in advanced decomposition can be collected for entomological examination. The temperature of the cadaver ideally should be recorded while the inquest is being done and it has to be measured by the police officers. If that's not done, then it has to be taken by mortuary attender before placing the body in cold chamber after inquest. This temperature and the time when the body was kept in cold chamber are desirable to be noted at least in cases where time since death is a moot point. These findings can be compared if required with the post-mortem changes. But one has to be very careful regarding the progress of post-mortem changes when the body has been subjected to cold room storage. This is why a preliminary examination of the body comprising of all the above said observations is necessary before keeping the body in the cold storage (at least in selective cases).

\section{Pre-evisceration stage:}

Blood if required can be taken from the heart by performing a cardiac puncture [2] with a syringe and long sterile needle but the recommended site is usually from a femoral vein. Hair samples when needed can be taken in this stage before putting incisions. Skin incisions are usually done with a scalpel [2] (having a disposable knife). Old literature mentions use of an autopsy knife with a 10-15 cms long blade for skin incisions [3]. Such autopsy knives are practically not easy to use since it requires constant sharpening before each autopsy on carborundum stone. Finally, the prosector has to face the brunt of using blunt instruments for dissection especially on those days when the case load in high. The authors recommend the use of disposable scalpels for the purpose of skin incisions. They are also known as "Bard-Parker knifes". While using any sharp instrument for dissection, the prosector have to use at most caution to not to injure his/her own hands.

Autopsy incisions [2, 4, 5]:

(a) I - shaped incision - This is the classical incision (midline incision) and is almost a straight line from laryngeal prominence to the pubis with a deviation around the umbilicus in order to avoid cutting it (Fig. 2 ). The upper end of this incision should not preferably extend above, until chin (as mentioned in older literature) since even a high neck shroud or collar will fail to cover the suture line from relatives. The pressure during putting such an incision can be at a medium level from chin to sternal notch; whereas further down until it reaches the solar plexus (upper one third of abdomen) sufficient pressure can be applied. Rest of the incision has to be done carefully as we do not want to puncture the peritoneal coverings or intestines (especially if the abdomen is slightly bloated). Insert two or three fingers (of the non-dominant hand) and lift the abdominal wall skin including the subcutaneous tissues and then continue the incision downwards till pubis. 


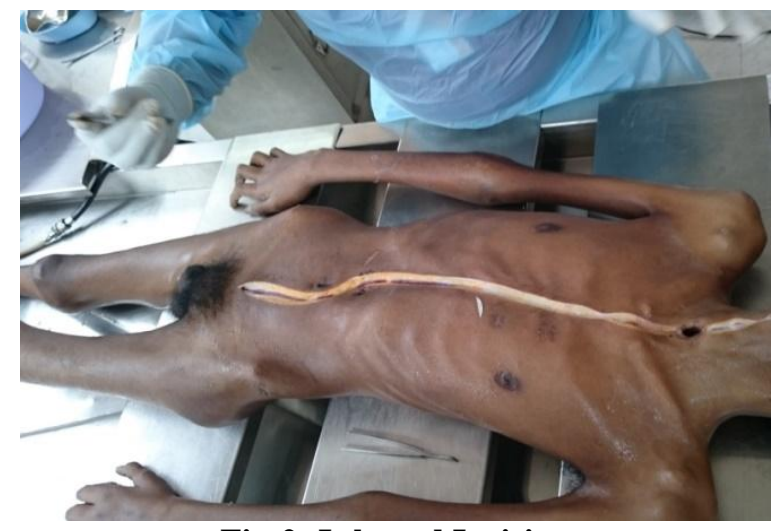

Fig-2: I shaped Incision

Lastly in case of the presence of any surgical sutures along the midline or anywhere on abdomen; leave them intact for being examined from under surface after opening up the skin.

(b) $\mathrm{Y}$ - shaped incision - The incisions begin on each side from behind each ears (forks of the ' $\mathrm{Y}$ ' and sometimes these forks are also called as ' $\mathrm{V}$ ' shaped incision) extending downwards to the mid-point of the collar bones (manubrium) and extending along the midline through sternal notch downwards till the pubis. This is required to inspect the face in situations of deep bruising or bony damage. The anterior neck and facial skin can be removed completely intact. This can be done to provide a wide raised approach to the neck structures. The authors perform modified 'I incision' approach to expose the neck structures as that is the conventional as well as convenient yet flawless method practiced amongst some of the subject experts. The I incision is only put from sternal notch to the pubis (Fig. 3 )and later after blood has been drained from all the body and cranial cavities (to avoid congestive artefactual haemorrhages - Prinsloo and Gordon); the same incision is extended upwards from the sternal notch to the chin/laryngeal prominence for neck dissection (Figs. 4, 5 and 6).

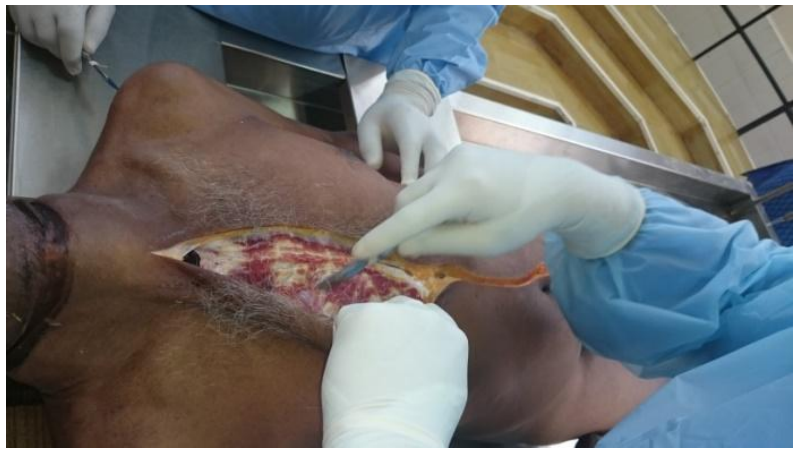

Fig-3: I incision from sternal notch

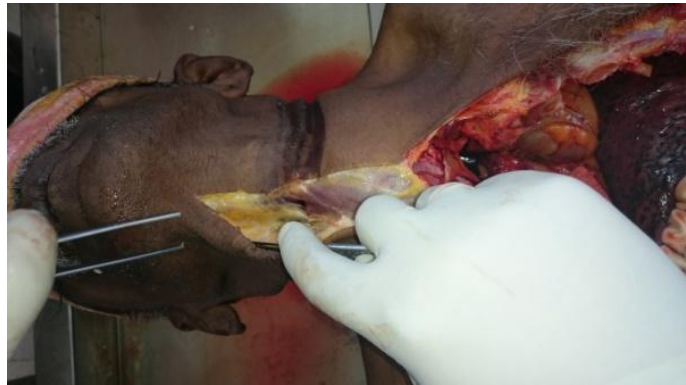

Fig-4: Extending I incision upwards

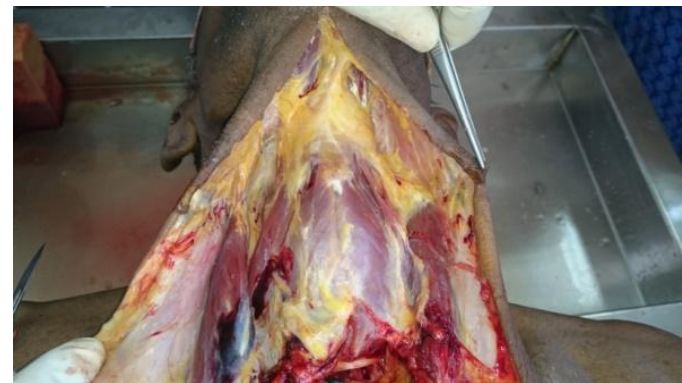

Fig-5: Exposed neck structures

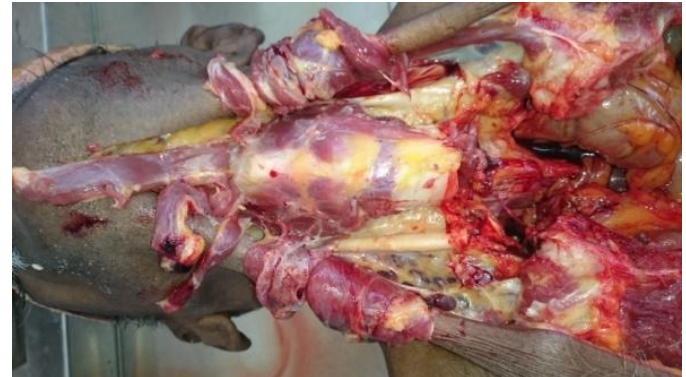

Fig-6: Examination of superficial neck muscles

(c) Deep U - shaped incision - It begins on both sides of the body from the outer ends of the collar bones (sub-clavicular incision) and extends down around the outer and lower aspects of the breast tissues reaching medially at the solar plexus and continuing down along the midline as almost a straight line around umbilicus terminating at the pubis. Sometimes instead of extending down around the breast tissues, this incision from the outer end of clavicles can extend medially to a midpoint few centimetres below the manubrium and can continue down along the midline when it will be just a ' $U$ ' shaped incision and not a deep ' $U$ - shaped incision. These incisions also provide a wide approach for inspection of the neck structures, but in general the $\mathrm{Y}$ incision or the modified I incision are preferred by the subject experts for detailed examination of neck structures.

(d) Cosmetic incision - The coronal incision (detailed under 'removal of brain') on the head on both sides are continued from behind ears downwards to back aspect of the shoulder and then curved downwards continuing through the mid-axillary line further downwards till the pelvic or even up to the lower portion of the buttocks. The entire skin and subcutaneous tissue can be reflected thus from the back 
aspect of the body. Similarly, the front portion of the trunk skin can be incised by continuing incision of the scalp along the front portion of the shoulder, axilla and continuing down the mid-axillary line till the pelvic brim. As the name suggests it is meant for not exposing the sutures while the body is being handed over back to the relatives for cremation/burial. The other advantage of this type of incision is to expose areas of contusions especially if deep seated/delayed on front/back aspects of the body. If required, the authors feel that such incisions can be extended to lower limbs too, which are vital areas to be not missed for examination in situations like custodial deaths.

Exposing the body cavities [2-4]: Once the skin incision of choice is made, the skin along with the subcutaneous tissues and fat are removed out from along the main incision. This is done till the lateral edge of the neck and inner two third of the collar bones are exposed. Caution is advised especially when using the scalpel at lateral edge of the neck since the tip especially or the edge of the blade can tear the skin causing "button holes". At the region of the front of the chest, the tissues including the pectoral muscles should be flayed off till the mid-axillary line. The anterior abdominal wall is similarly separated. It is preferred to reflect the entire skin, subcutaneous fat and muscles while dissecting abdomen. From the middle (lengthwise) of the main skin incision, the anterior abdominal wall muscles are separated. The left index and middle fingers are inserted with the palmar surfaces facing upwards. The fingers are separated in a ' $\mathrm{V}$ ' shape and abdominal skin with subcutaneous tissues is lifted thereby shielding the underlying soft structures (Fig. 7). Next, the scalpel can be used to separate the muscles and tissues by incising them from within the limbs of ' $\mathrm{V}$ ' shape of the fingers downwards till the pubis. The abdominal cavity is thus exposed (Fig. 8). Transverse incisions can be made on the inner aspect of the reflected abdominal flaps on the lower aspect without letting the incisions to come out through the skin. This is to rule out any deep-seated contusions, which are not visible externally or even internally after reflected the flaps.

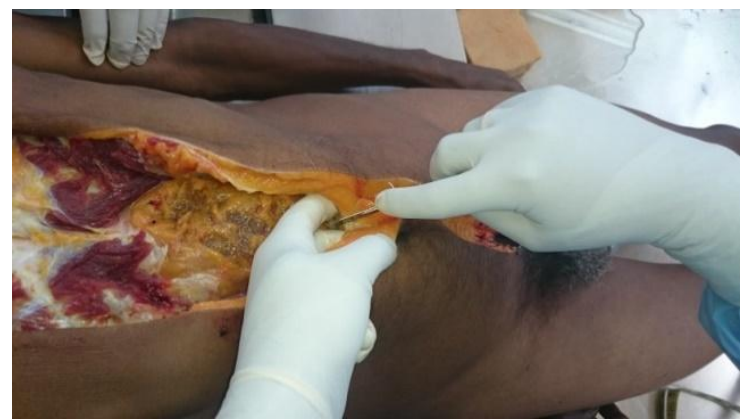

Fig-7: Careful dissection of the subcutaneous tissues

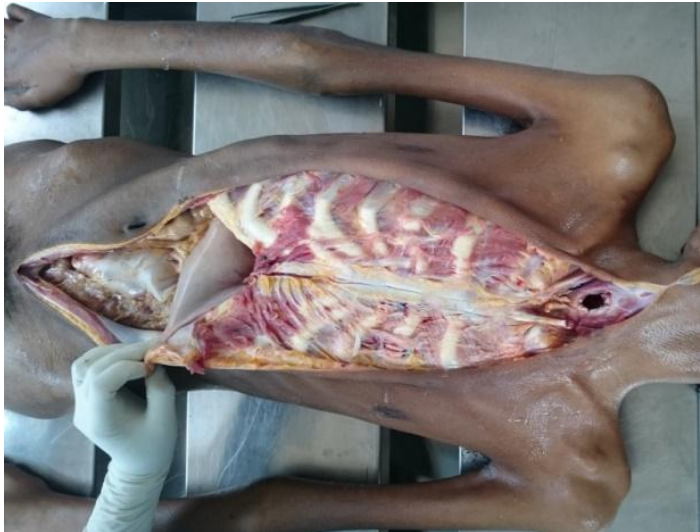

Fig-8: Abdominal cavity opened

After ruling out pneumothorax the chest cavity is exposed. This can be done by removing the breast plate / sternum. Using the scalpel, by guiding it with index finger towards under surface of the sternum the incisions are made from second rib downwards till the last rib; about $1 \mathrm{~cm}$ outer to costo-chondral junctions (both the sides). The under-surface tissues/organs are to be protected from cuts by not dissecting too deep. These cartilaginous junctions can be cut easily with one stroke except in elderly individuals. In case of calcified junctions, we can use rib shears (Fig. 9). This is the only instance so far when we require a different instrument for proceeding with the dissection procedures. The blunt end of the rib shears can be passed beneath the breast plate to protect the soft tissues beneath. In order to remove the sternum, it has to be disarticulated at the sterno-clavicular joints as well as from the first rib. This is a bit tricky. The arm of the cadaver has to be moved by the prosector to identify the sterno-clavicular joint capsule. Then the scalpel can be directed vertically downwards into this capsule and cut laterally in a half-circle fashion to separate this joint on both sides (Fig. 10). The scalpel is then directed deeper and downwards to cut attachment of first rib with sternum, $1 \mathrm{~cm}$ outer to the attachment of second rib with sternum.

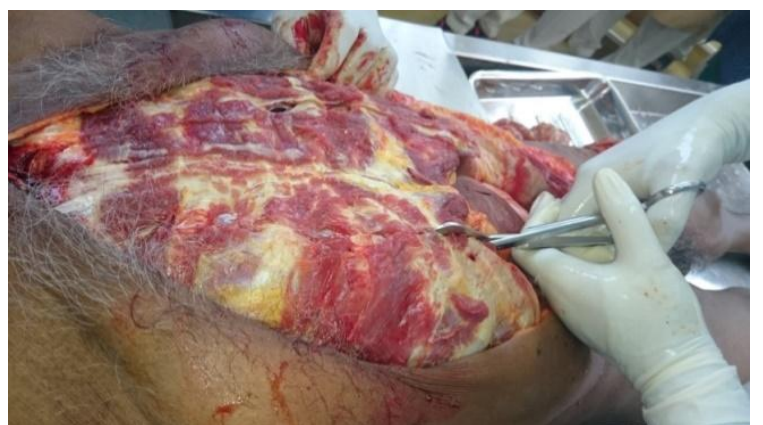

Fig-9: Rib shears for calcified costo-chondral junctions 


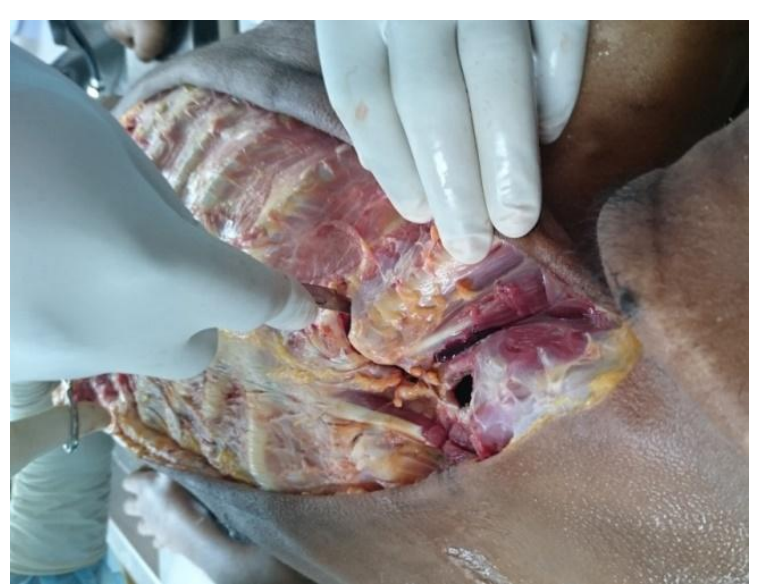

Fig-10: Dissection around the sterno-clavicular joint

Rib shears can be used in case if these joints are calcified. In cases of extreme difficulty, a mallet and chisel can be used but with extreme caution as to not to damage the soft tissues or blood vessels underneath or the nearby structures. The use of these instruments should not be made a regular practice and must be avoided when the chest cavity exposure is of at most importance in certain cases. Lift the sternum gently by grasping its lower edge. Simultaneously horizontal cuts are made on the under surface of the sternum thereby detaching it from the mediastinal soft tissues. The blade should be slanted and directed towards the under surface to protect the soft tissues such as pericardium beneath. The sternum is then lifted with the left hand and the right hand is used to examine the pleural cavities on both the sides for presence of fluids or adhesions. After this the sternum is manipulated by series of up and down strokes to disarticulate it completely from the clavicle / collar bone (Fig. 11).

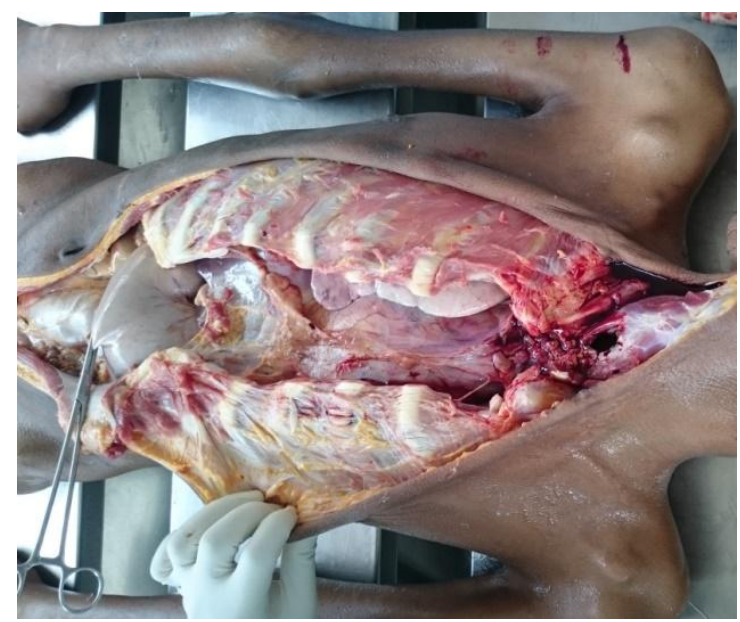

Fig-11: Chest cavity exposed

Testing for Pneumothorax [2, 4]: After reflecting the front portion of the chest, till the midaxillary lines, water is poured into the angle between the subcutaneous tissue flap of skin (the flap being held outwards with left hand of the prosector) and using the scalpel held in the right hand the intercostal tissues below the water line are pierced. If pneumothorax is present (in cases of trauma and in certain respiratory ailments) then bubbles of air will be seen rising through the water. The water can be then drained out of the cavity. Alternatively, a $50 \mathrm{ml}$ syringe having a wide bore needle can be used to test for pneumothorax. It should be filled with water after removing the plunger. Then the needle should be pierced into the pleural space and water should be watched for presence of bubbles. Another alternative method (mentioned for completion sake) is to take post-mortem chest $\mathrm{x}$-ray and to assess pneumothorax like it is done for a living patient.

Demonstration of Air Embolus [2]: Air emboli in routine cases are not ruled out by a chest $\mathrm{X}$-ray prior to the beginning of autopsy procedures. This is because the same can be demonstrated during the dissection. The large neck veins should be left intact if to demonstrate air emboli properly. The pericardium is opened and it is filled with water. Once the heart is fully submerged in water, the right atrium and ventricle are incised and the prosector should look if any air bubbles escape through the incisions. The water filled syringe procedure (similar to demonstration of pneumothorax) can be also used in this context.

\section{Evisceration:}

Basically, there are four evisceration techniques to examine the thorax and abdomen. The method of choice depends on both the circumstances leading to death as well as the findings anticipated by the prosector.

\section{Letulle's En Masse Dissection [2, 3, 4]:}

This method involves removing almost all the internal organs at one time. According to the authors, this evisceration technique is the most commonly performed one in medico-legal autopsies. It may require assistance depending upon the prosector and is a rapid technique of removing all organs at a time from the body; though the dissection can be lengthy. All the attachments and relationships between the organs are left intact. The only drawback of this method is the large conglomerate of organs placed outside the body for dissection. Sometimes inexperienced hands doing this method can make it very time consuming.

In the pre-evisceration stage both the body cavities (chest and abdomen) were inspected. Next the omentum is lifted up and placed backwards on to the lungs. Since the intestines obscure the abdominal part of the dissection, they are usually removed separately before the other organs. The intestine coils are exposed. Uppermost part of the jejunum is identified using the right hand of the prosector. It passes retroperitoneally to join the terminal end of the duodenum. Once this portion is identified; it is lifted and resected using the scalpel blade. Before resecting, the contents if any can be milked down to the distal portion. There is no absolute essentiality to tie twines on both sides of the 
resection because practically no contents are lost while cutting without tying the ends and hence attempting to tie ends is a mere wastage of time. The small intestine is then stripped off by asking the assistant to pull out the intestinal loop with a reasonable force from the point of resection. Simultaneously the prosector uses the scalpel (in a continuous sawing motion) to cut along the mesentery of the coils as close to the loops as possible. The left hand of the prosector is used for holding the resected mesentery (attached to stomach etc.) within the cavity (Figs 12 and 13).

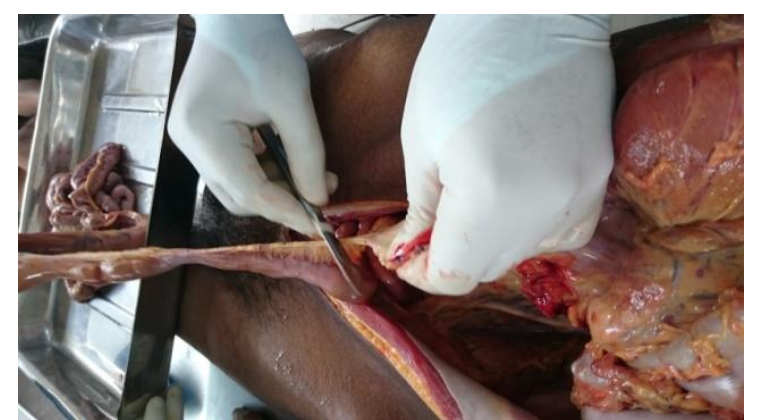

Fig-12: The mesentery being severed in a sawing motion

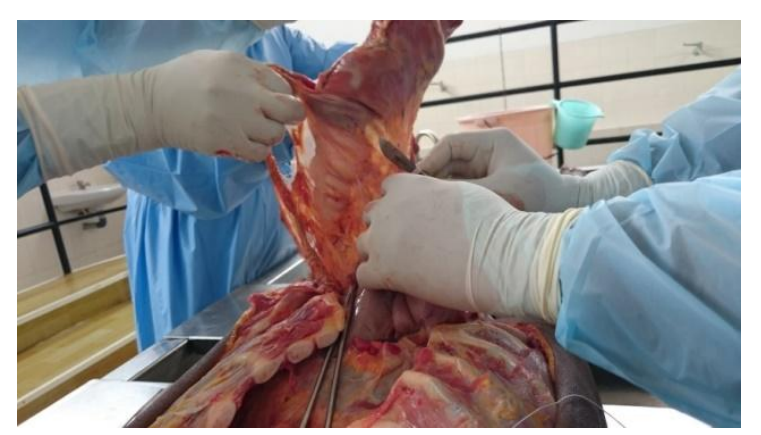

Fig-13: Inspection of the intestinal loops

The loops as resected are examined properly by the prosector. Once the ileocaecal junction is reached; the assistant is asked to mobilize the caecal region. The assistant is asked to provide sufficient manual traction to the caecal region by pulling the intestine portion towards his/her side. The appendix can be visualized and the scalpel is used to make incisions to separate the ascending loop of large intestine from the abdominal cavity. On reaching the hepatic flexure the assistant is asked to pull down the transverse colon. Holding the mesentery and stomach well protected in the left hand of the prosector incisions are made to separate this portion of the intestine from the cavity. After reaching the splenic flexure the assistant can pull the descending colon downwards and medially while the left hand of the prosector can be used to shield and keep the spleen and adjacent tissues intact. The right hand of the prosector can be used to resect the intestine loop. At this portion the pulling force is strictly speaking sufficient rather than dissection to remove the intestine from the abdominal cavity. Once the sigmoid colon is also detached from abdominal wall; it need not be resected from the rectum always. If the intestine needs to be opened for further detailed examination; then resection can be done between sigmoid colon and rectum and the entire intestine loops can be transferred to a trough. Then the loops can be resected and can be inspected piecemeal. Otherwise the intestine is left connected to the rectum so that later it can be placed back into the abdomen while suturing the body after post-mortem examination.

When the pleural cavities were examined while removing sternum the organs in the chest are ensured free of attachments/adhesions. If there were adhesions they are cut through or are stripped off using scalpel or using hands. Further the diaphragm and other attachments in the abdomen should be excised. The assistant can put his/her left hand into the right pleural space as abdomen should be excised. The assistant can put his/her left hand into the right pleural space as well as right side of the abdomen and pull towards his/her side the liver and adjacent tissues placing the diaphragm in the web spaces between the index and middle fingers. Then s/he can cut the diaphragm as close as possible to the central portion at the back aspect of the abdominal and chest cavities (Fig. 14). As the diaphragm is resected, the cut curves backwards and reaches the spine where it is further cut through the ligaments to reach the kidney. The kidney is also then pulled upwards and towards the assistant and is freed of its attachments within the abdominal cavity. Finally, the psoas muscle is resected at the level of the pelvis. The same steps are followed on the opposite side where the spleen is located and the prosector does this time the procedures on the left side of the cadaver. The prosector and assistant can help out each other by pulling the rib cage towards their side when the person on the opposite side is resecting the diaphragm. The bladder may be opened widely after urine (if required) is collected in a sterile manner. The mucosa and trigone are inspected and then the prostate is incised for examination. Whereas in females, the uterus and appendages are pulled out in traction and cut should be made through the soft tissues of the upper vaginal wall. The scalpel can be used to incise the laterally extending soft tissue attachments thereby freeing the entire uterus and its appendages. It is removed from the abdominal cavity for dissection and examination later.

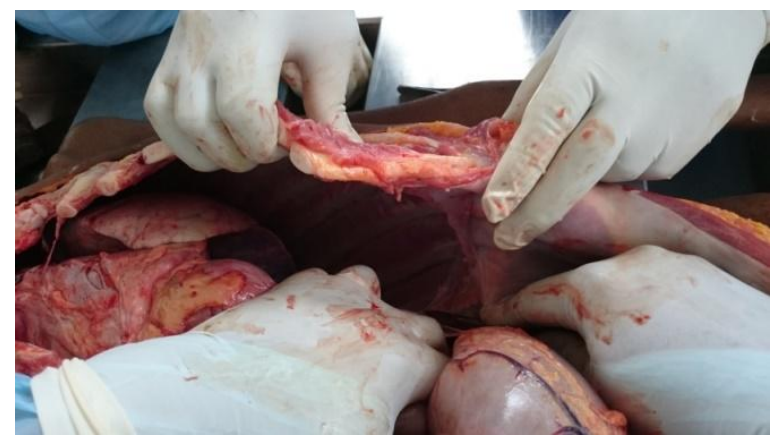

Fig-14: Dissection of the diaphragm 
To free the neck structures, a wooden block (10 - $15 \mathrm{cms}$ high) should be placed under the shoulders and on the shoulder support. This allows the head of the cadaver to fall backwards providing maximum extension of the neck. While the wooden block is being placed, neck can be examined for any hyper mobility as a result of ante mortem fractures or neck injury. At the same time undertaker's fracture (post-mortem subluxation between C6 and C7) must not be produced due to careless handling of the cadaver. The neck structures need to be freed. The scalpel is inserted into one side of the exposed neck until it enters the floor of the mouth. It is then run around the inner sides of the mandible to free the attachments at the floor of the mouth. The left hand is introduced deep into the floor of the mouth to grasp the tip of the tongue to pull it out simultaneously ligating any attachments that may still be holding back the tongue and neck organs. The tip of the tongue is seized with a toothed forceps or an artery forceps to pull it out more efficiently (Fig. 15). A set of strong fingers will serve the same purpose (in the experience of the authors). The scalpel in the right hand is placed inwards such that the blade pierces the soft palate. Then the soft palate and the uvula are dissected from the hard palate. The dissection is continued thereby separating the midline structures of the neck from the spine. Simultaneously traction is applied holding the tongue and the midline structures of the neck. The common carotid arteries on both the sides of the neck are left intact along with the spinal column. At the inlet of the thorax, the soft tissues and the other blood vessels can be severed (extending to the medial under surface area of the collar bones) using the scalpel.

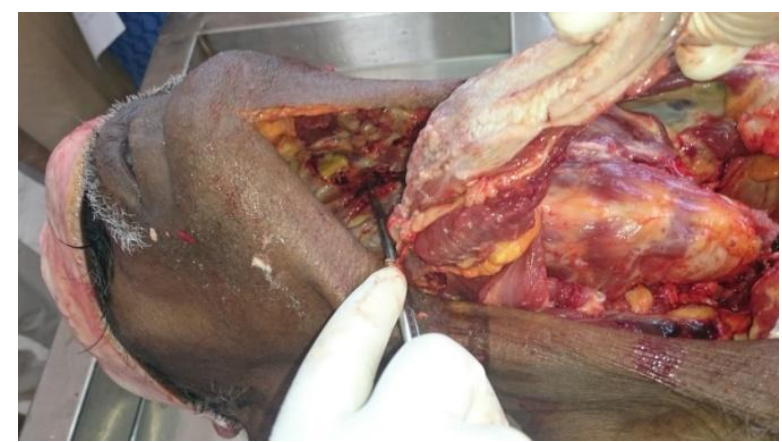

Fig-15: Pulling out of the neck structures holding the tongue

The complete visceral conglomerate is free from attachments and is pulled out carefully (Fig. 16). Sometimes the prosector has to free the aorta from the posterior attachments to the spinal column. Lastly the only attachments at the lower portion of the abdomen i.e. the iliac vessels and the ureters are dissected whereby the entire pluck of viscera can be laid on the adjacent wooden dissection board. The neck structures will be away from the dissection field of the prosector and kidneys vice-versa. The back aspect of the visceral conglomerate will be facing the prosector. (Fig. 17) This means the position of the organs on the dissection board will be corresponding to the position of the body when it is prone. The entire chunk is rinsed with water prior to dissection / examination of individual organs.

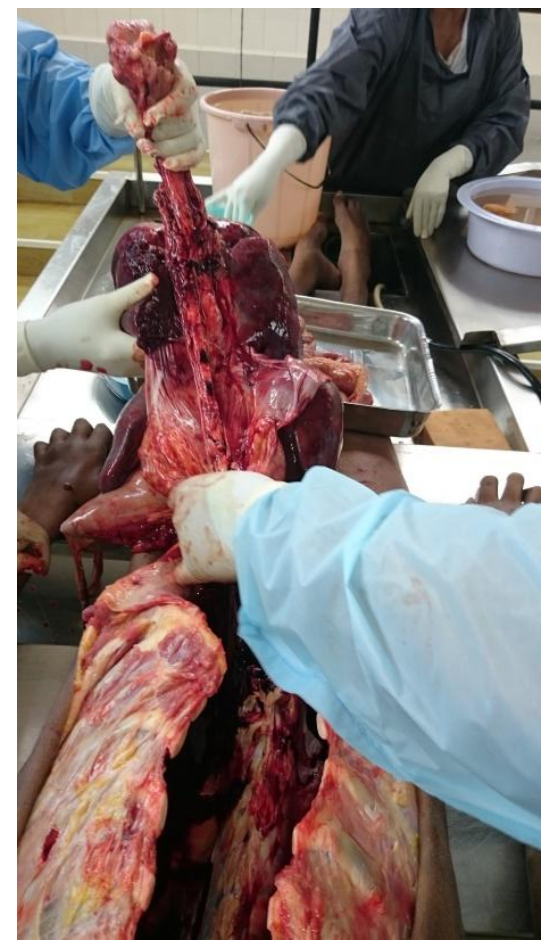

Fig-16: Evisceration of the visceral conglomerate

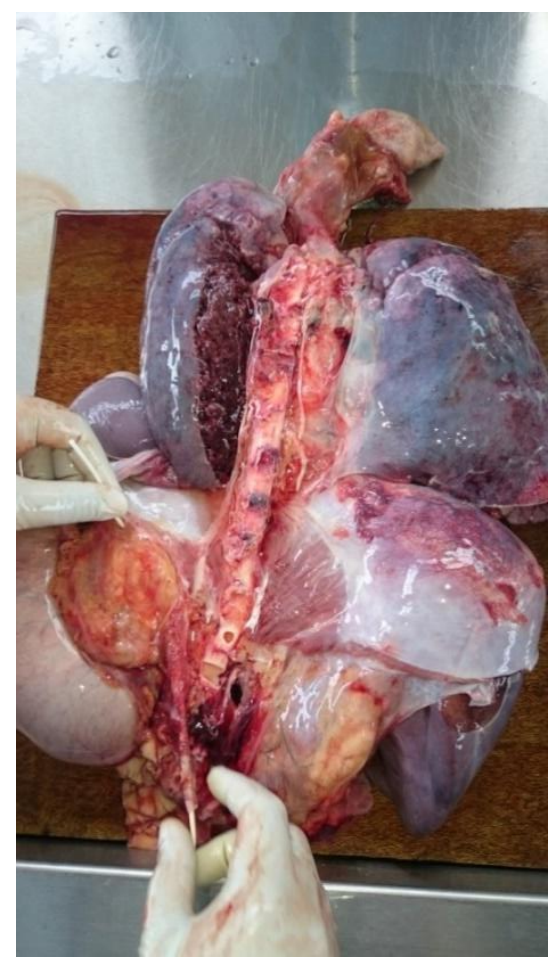

Fig-17: Positioning of the visceral conglomerate prior to the detailed examination

\section{Ghon's En Bloc Dissection [2]:}

This second method is a modification of the method described originally by Ghon. It involves extracting the organs in four or five separate blocks 
(plucks): the thoracic pluck (neck structures, heart, lungs and mediastinum); the coeliac pluck (liver, stomach, spleen, pancreas and duodenum); the intestines; the urogenital block and last but not the least the neurological system as fifth block (if necessary).

Here the inter-organ relationships can be readily observed and demonstrated with simplicity. If unexpected pathology is encountered at the level of separation of the various plucks (eg. oesophageal varices), it could be destroyed due to this dissection technique. Block dissection can be combined with 'En masse' dissection as and when the situation demands.

\section{Virchow's Dissection [2]:}

This is simply the removal of individual organs one by one followed by dissection of that isolated organ. The individual organ pathology can be assessed and this method is extremely quick and effective if the prosector is interested only in a single organ. But if pathologic abnormalities are seen in several organs, then the case relationship will be difficult to interpret as the anatomical relationships are destroyed.

\section{Rokitansky's Dissection [2]:}

Although the literature mentions this method to be rarely performed, in experience of the authors, following 'En masse' dissection this is the most popular dissection technique practiced. This method involves dissecting the organs in situ with little actual evisceration prior to dissection. However, by practicing this technique the amount of information obtained from the cadaver will be limited. But the dissection would be speedy and the method can be time saving if the prosector doesn't expect anything great by way of information from the cadaver. This method is routinely practiced if the cadaver is a source of highly transmissible disease and more commonly in cases of advanced putrefaction. This is because in latter almost all the internal organs will be converted to a pultaceous mass. Hence the other three dissection techniques will be fruitless and wastage of time in such cases.

\section{Removal of the Brain [2, 3, 4, 6]:}

We cannot forget this body cavity; the cranium. The neck of the cadaver can be placed in the notch of a head rest after removing the wooden block from beneath the shoulders. If the CSF needs to be collected prior to removal of the brain, a cisternal puncture can be done to aspirate the same. The head can be turned to a lateral position and flexed as much as possible. The assistant can be entrusted with fixing the head in this position by holding it firmly. The skin above the spine of second vertebra is sterilized and a special spinal needle is inserted. The needle is held steadily in that position using thumb and is pushed in an upward direction along the midline, using the top portion of the external ear as a reference point. If the needle happens to strike the occiput, then it can be withdrawn, depressed and further pushed in to enter the cisterna magna. The distance from this cisterna magna back to the skin is usually only 4 to $5 \mathrm{cms}$. Alternatively, CSF can be collected after evisceration by opening up the spinal canal anteriorly and aspirating using a needle and syringe. It is also possible to collect CSF from the ventricles (preferably lateral ventricles) after removal of the skull cap by passing a long needle through the surface of the brain. Lumbar puncture postmortem frequently results in dry taps.

The scalp should be examined by the prosector for possible wounds, haemorrhages, skull fractures etc. prior to making an incision. In cadavers with abundant hair, it is parted with a comb to obtain a path for incising the scalp. It is often helpful to wet hair. The incision is put with the scalpel from the mastoid process behind ear, to the vertex crossing the parietal bone areas of skull over to the mastoid process of the opposite ear in a semi-circular pattern. This is coronal incision. When a modified Y-shaped incision is adopted, the incision on the scalp is an upward continuation of the same from the forks of the ' $Y$ '. The scalp up to the galea aponeurotica layer is dissected out/separated from the skull by reflecting in both directions from the line of the incision (Fig. 18). The reflection of the scalp is continued to a line parallel to and about 1 to $1.5 \mathrm{cms}$ above the eyebrows of the cadaver at the front aspect. It is continued till the occipital protuberance at the back aspect. When facial injuries require deeper examination, the anterior reflection may be extended further forwards reflecting entire skin of face till neck without perforating the facial skin (so that proper restoration of facial skin is possible). Similarly, the scalp can be reflected more posteriorly till the nape of the neck to examine for any similar injuries. The bones have to be sawed through to remove the skull cap. Using the pointed end of the scalpel blade the proposed path of cutting out the skull cap has to be marked at the anterior portion of the calvarium starting from just above the ears and across the frontal bones. The posterior path extends from the inferior end of the anterior path continuing over the occipital bone above the superior nuchal lines to meet the path from the opposite side. The junction of the lines above the ears forms an obtuse angle of 100 to 120 degrees. This means the entire path is never a circumference as it is almost an impossible task to restore the head without unsightly sliding of the calvarium. Another matter of fact is that it is at this junction (of anterior and posterior paths) the scalpel blade also cuts the temporal muscles which if preserved properly can be utilized to suture later to keep calvarium in place. 


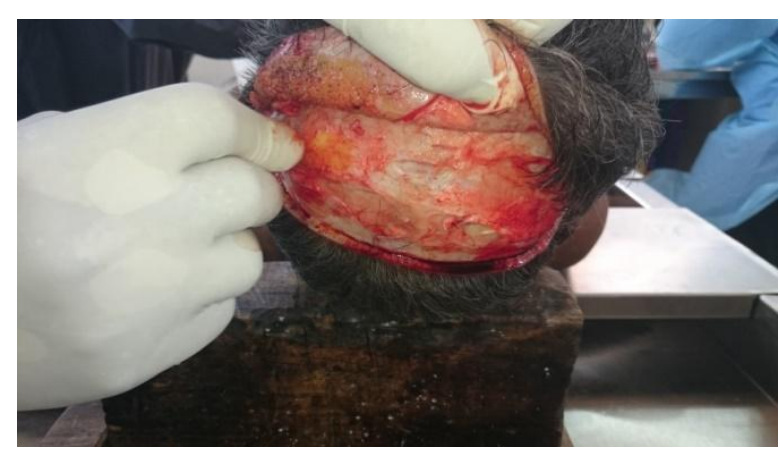

Fig-18: Reflection of the scalp

An electric saw (rotatory or vibratory) is required to open the skull along the paths made. The rotatory (Stryker saw) blade type should be covered by a shield to prevent the spread of the bone dust. Actually, the vibratory (oscillatory) saw is preferred since it does not spread bone dust and produces less accidental injury to the person using it (in the experience of the authors). Using an electric saw requires a certain amount of practice. Contamination of the air with bone dust can be prevented by continuously dripping water on the bone at the site of sawing. Proper care has to be taken to prevent cutting through the meninges and the brain. This can be tackled by not sawing through the entire thickness of the skull but to stop when the saw meets through very little resistance. In case of skull fractures with or without scalp injuries, they have to be noted and photographed if required prior to the dissection. As far as possible the existing skull fractures should not be confused with or mixed with artifacts produced while sawing the skull for opening the calvarium. The same reason as to not to produce fracture artifacts is why a hammer and chisel is not recommended to break open the skull cap. Once the saw cuts through the skull along the designated path, then the wedge-shaped portion of calvarium/skull cap is removed using leverage. For obtaining this leverage, minimal assistance can be taken from a chisel and hammer. Chisel can be inserted to the gaps and hammer can be used to tap to completely separate the skull cap. The hook of the hammer can be inserted into the gaps to pull off the cap (Fig. 19). The inner surface of the skull cap and the dura surface can be inspected. Sometimes the dura mater being adherent gets pulled off as we remove the skull cap.

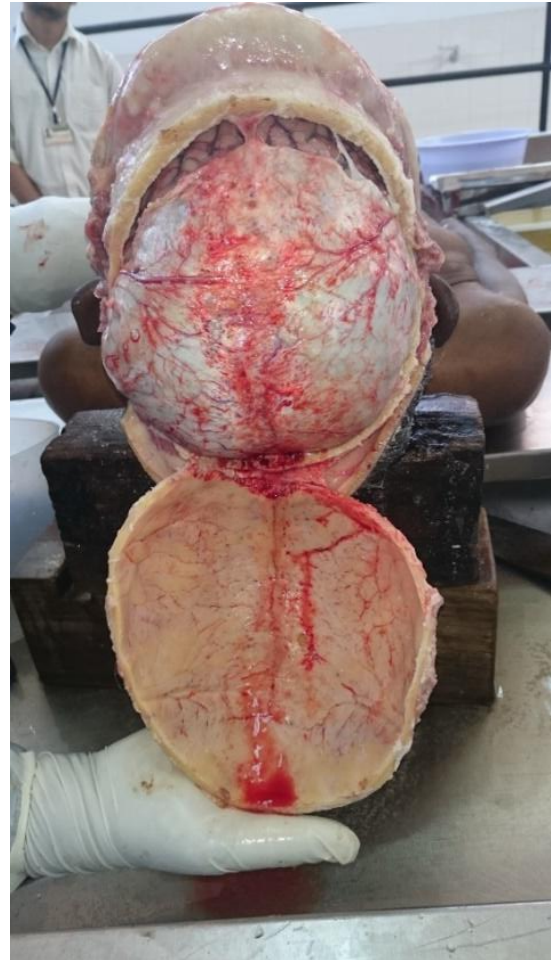

Fig-19: Skull cap after opening

Removal of the dura mater can be done in two ways. After examining the surface of the dura mater, a midline incision can be put along the superior longitudinal sinus (superior sagittal sinus) with the scalpel. This is to investigate the presence of possible thombi. Two small horizontal incisions can be made in the dura, one to the left and the other to the right of the mid-line in the region of the frontal lobes. The dura mater can be held with a toothed forceps (thumb forceps with serrated tips) at these openings and incised to both sides using a scissors with one end semi-blunt (Mayo scissors). The line of incision corresponds with the line along which the skull cap was opened. The semi-blunt end (to protect the brain parenchyma) of the scissors is introduced through these small openings into the sub-dural space for incising to both the sides. The dura is then freed anteriorly from the cribriform plate by cutting the falx at its insertion into the crista galli. Then the dura is withdrawn from anterior to the posterior direction and is left hanging over the occiput attached to the remainder of the dura that covers the base of the skull (Fig. 20). Alternatively, if the prosector doesn't suspect any presence of thrombi; not necessitating the midline incision, along the superior longitudinal sinus; then the dura can be removed omitting that step and following the rest as enumerated above. 


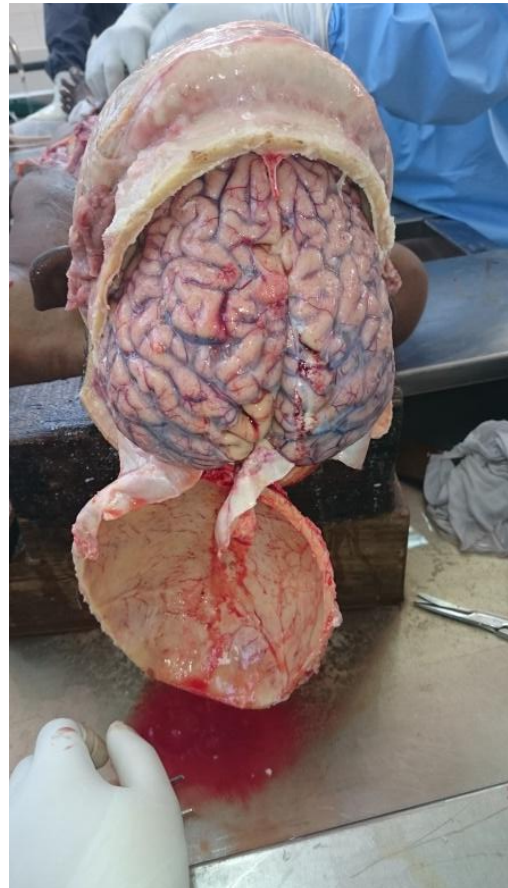

Fig-20: Brain exposed after removal of the dura mater

The frontal lobes of the brain are accessible now. The left hand of the prosector can be placed gently in front of these lobes using two to four fingers placed on either side of the midline and brain is edged away from the base of the skull by lifting the frontal lobes. All the cuts will be performed on the under surface of the brain by gradually pulling it back simultaneously supporting the brain from behind. The assistant can be asked to support the brain from behind. The left hand of the prosector can be used to provide a downward and backward traction to the brain. The right hand of the prosector using the scalpel can do the dissection. At first the olfactory nerves are easily seen as brain is lifted and they come off free without requiring any dissection. The optic nerves that come next are transected as far as possible close to the base of the skull (Fig. 21). Following this the internal carotids are resected next (inspecting for thrombus/atheroma) followed by the pituitary stalk and oculomotor nerves. The temporal lobes of the brain are then lifted and the tentoria cerebelli are cut from anterior borders using a scalpel with incisions directed outwards from the midline (Fig. 22). It is done on both the sides of the skull until the lateral wall of the skull is reached (as close as possible to the petrous part of the temporal bone). The prosector should be careful to not to injure the cerebellum beneath. The assistant (especially if inexperienced) must be alerted to support the brain which now falls more backwards. This is to avoid rupture at level of pedunculi cerebri. Brain stem is now partially visible. The remaining cranial nerves are identified and severed as far as possible from the brain. After this the assistant can be relieved of his duties and the left hand/non-dominant hand of the prosector him/herself can be used to support the brain from behind. The scalpel is then introduced through the foramen magnum into the cervical canal. The spinal cord is severed (along with the vertebral arteries) as distal as possible with a single swiping motion.

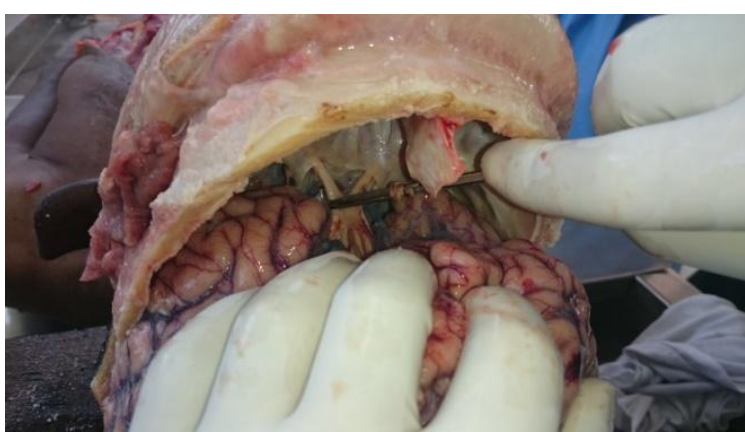

Fig-21: Transection of base of the brain structures (optic nerves at chiasma)

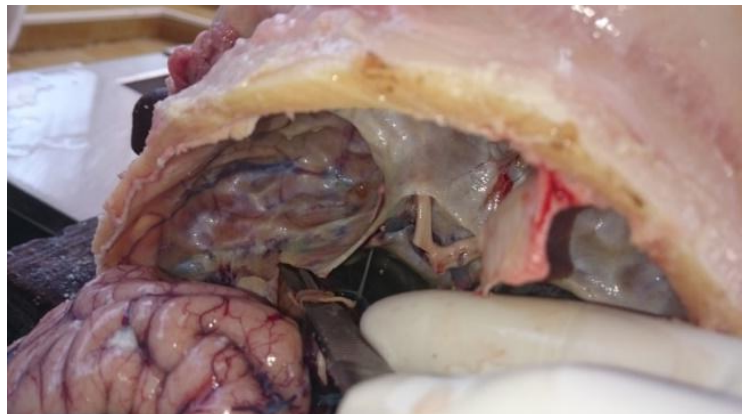

Fig-22: Cutting through the tentorium cerebelli on left side

The brain can be delivered by letting it fall back into the supporting non-dominant hand slowly and simultaneously holding its under surface (which is now facing upwards) with the right hand. The occipital portion of the brain to which the dura is adherent can be separated by gently pulling out the brain from the skull cavity. After removal of the brain it is weighed and the surfaces are examined (especially the base of brain). Then it is placed gently on a wooden board; its convexity in view of the prosector and the frontal lobes directed away from him/her. One must be very careful while handling fresh brain, since it is very soft and tears easily. Dissection and further examination of the brain can be also done when required after fixation of the brain in formalin. A container (eg. plastic bucket) can be half filled with 10 percent formalin solution. A long twine can be passed through between the 'Circle of Willis' (usually basilar artery) and under surface of the brain. After this the brain can be suspended (convexity facing downwards) in the container after fastening/securing the ends of the twine to the edges of the container. The brain is allowed to harden in the fixative for preferably for a month with several changes of formalin. In authors' experience, injecting 10 percent formalin into the intact 'Circle of Willis' and or into the brain parenchyma randomly has helped for proper complete fixation of the brain tissue. Otherwise the deeper tissues of the brain would have not fixed 
properly due to poor penetration of the fixative. Such areas on dissection would be light brownish - pink in colour (early putrefaction).

Following removal of the brain, the pituitary fossa is inspected. It will be covered by the diaphragma sella. The posterior wall is formed by the sphenoid bone and this is forcefully broken using an artery forceps (rat-toothed or serrated tips). Dura mater is detached posteriorly and the scalpel blade can be inserted into the pituitary fossa (from the side). The prosector has to carefully do this insertion as low as possible so that the pituitary gland can be elevated, delivered superiorly and dissected out completely without being crushed. Using the scalpel the inferior sagittal sinus, the transverse sinuses and the cavernous sinuses can be opened and examined. Now the dura covering the base of the skull needs to be removed. Using the artery forceps, clamp a descent good amount of the dura and wind the remaining dura onto the instrument away from the bone simultaneously using gently traction. While removing the dura one must be careful to not to disturb the existing ante-mortem fractures at the base of the skull.

\section{Removal of the Spinal Cord [3, 4]:}

This is rarely performed and if required the prosector must not hesitate to examine the spinal cord. There are several methods to remove spinal cord but due to the less practical scenarios that come up to examine the cord; the authors will briefly touch upon the basic steps for the sake of completion. In simple terms there are two different approaches to removal of spinal cord. They are the anterior approach and the posterior approach.

In the anterior approach, the procedure is done after complete en masse removal of the internal organs. The autopsy instruments so far discussed will be needed to remove the spinal cord. The pedicles of all the vertebrae are sawed and separated on both the sides thereby detaching the vertebral bodies and exposing the spinal canal. This can be started from below (level of promontory of the sacrum) after separating the attachments from psoas muscle as well as other ligaments. Once all the vertebral bodies have been separated; the anterior surface of the dura mater and the nerve roots are exposed. The spinal nerves are severed laterally and the dura mater is cut completely around and as high as possible (at level of foramen magnum). The advantages of this method are that the body need not be turned over on its face, an extensive dorsal incision is not required (leakage can occur) and the procedure is less time consuming.

The posterior approach is preferred to be attempted prior to opening up of the body cavities/viscera removal. This is because the trunk will provide adequate support. A towel (folded) can be placed beneath the face (for protection) if required and it is advantageous to place a wooden block under the chest. A midline incision is done from occiput to the lumbar region and the paraspinal muscles are reflected along with the subcutaneous tissues. All along the length of the spine on both the sides, two parallel sawcuts are made down the laminae. The spinous processes and the attached laminae en masse are removed. Care has to be taken to not to remove lamina of the first cervical vertebra as the head will revolve loosely on spine. The dura mater as well as the nerve roots is severed and the spinal cord is removed gently.

It is desirable to fix the spinal cord (in $10 \%$ formalin solution) prior to dissection and examination. The entire central nervous system (brain \& spinal cord) can be removed intact.

\section{Examination of Viscera/Organs:}

In the experience of the authors, order of examination of the organs/viscera should depend on the prosector. The prosector can use his/her judgement as to the decision of whether certain organs (of keen interest) need to be examined in the beginning. This can help the prosector to not to lose valuable findings. Even literature quotes that a definite order as to which system should be examined first cannot be fixed mandatorily [6]. Depending upon the lesions seen and the organs thereby required to be examined in priority, the entire order of examination can change accordingly. However, during examination, it is recommended to follow a proper routine whatever be the case especially if there are no important indications for a change in existing routine. This will ensure that nothing is left undone or unexamined as in the case of beginners who perform medico-legal autopsies $[4,6]$.

The order of examination outlined here will be a continuation of the en masse evisceration (as described earlier). The sequence of examination of the viscera/organs in the other evisceration techniques need not be as streamlined or systematic as in en masse technique. The weights of all the organs must be recorded before dissecting / or fixing them [3]. This is because weights can be changed or altered during dissection and fixation. It is preferable to use digital balances. The only exception is the heart, which must be first opened and cleaned off the blood clots; only after which it is weighed.

The dissection starts off with the retroperitoneal organs [6]. After washing the entire visceral conglomerate in a stream of running water and wiping with sponge, the lower ends of descending aorta (divided into iliac arteries) are held using forceps and opened using scissors. The entire aorta is then opened along its posterior wall up to the arch (Fig. 23). After washing off the blood clots the intima is carefully inspected. The aorta (till the arch) can be carefully removed from its visceral attachments and is placed in a tray. The lower end of inferior vena cava is next identified and this vessel is opened up along its 
posterior border as further as possible close to the right atrium (Fig. 24). Dissection is done carefully taking care to not to disturb any ante-mortem blood clots. Such blood clots if required can be preserved for histopathological examination at a later time. Now the prosector has to locate the adrenals. This requires some experience, especially to get used to finding them when embedded in perinephric fat. Frequently it gets inadequately removed or cut during dissection. Literature highlights on tracing adrenal veins to aid in identification of the adrenals [2]. These can be located with the help of renal veins and inferior vena cava. In the experience of the authors, the diaphragm muscle flaps have to be dissected out since they cover the kidneys and adrenals in the visceral conglomerate (though existing literature is silent about this aspect). After the diaphragm is dissected out, the right adrenal gland (triangular in shape) is seen just above the kidney adherent to the under surface of the liver and perhaps embedded in fat (Fig. 25). The left adrenal gland (crescentic in shape) is seen medial to the kidney on that side but it is almost always buried in the tissues between pancreas, spleen and kidney. Both the adrenals are carefully dissected out, kept on wooden board and are examined for bleeding or any other abnormalities by making incomplete vertical slices throughout the glands except for one border (to keep the glands intact) [2].

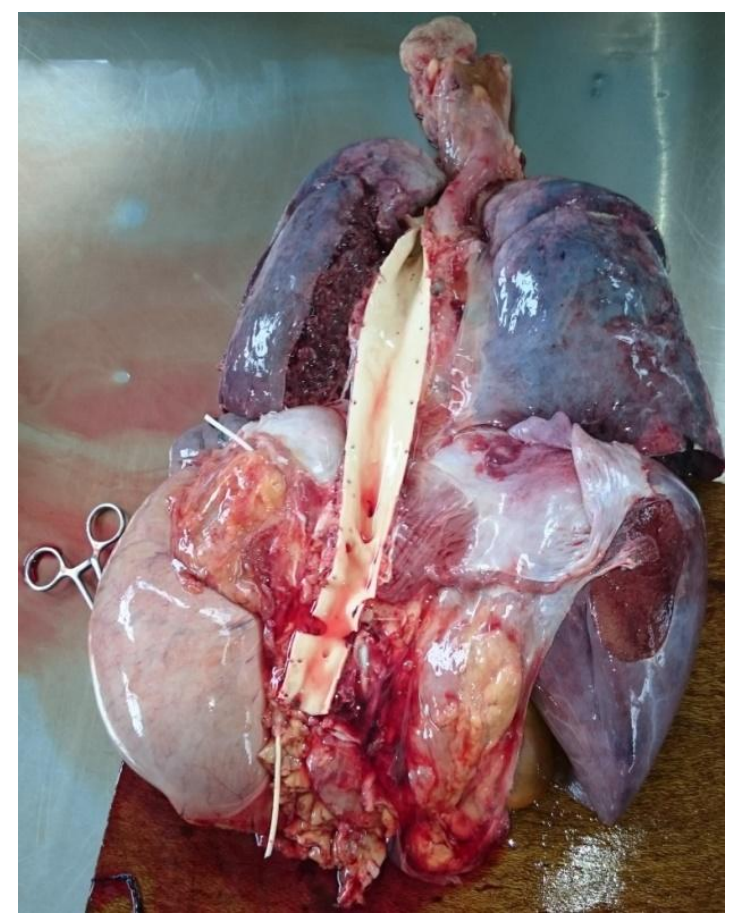

Fig-23: The aorta has been opened up for examination

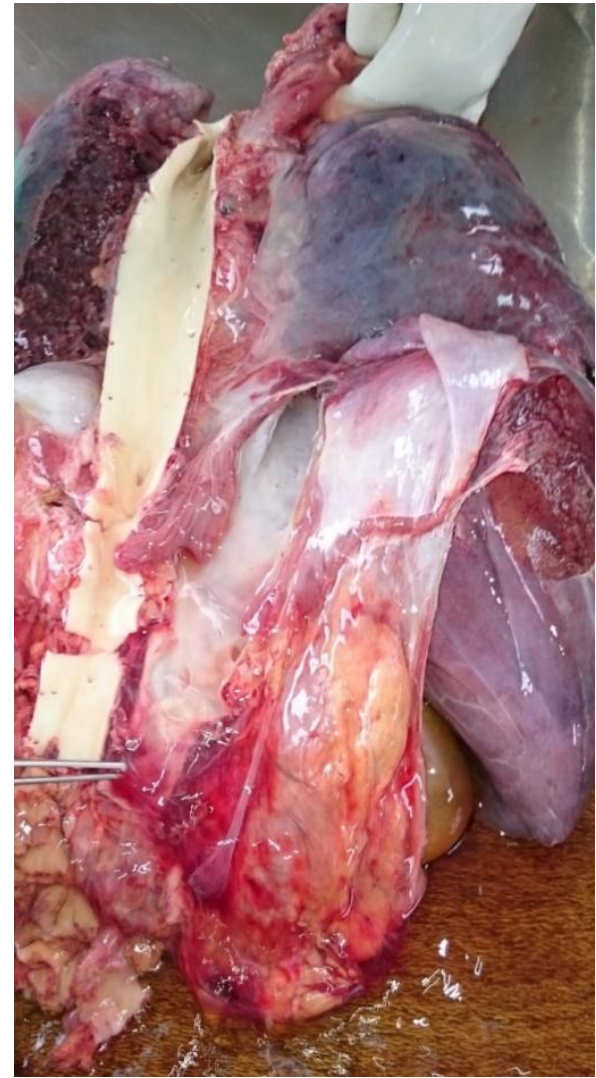

Fig-24: The Inferior vena cava after being opened up with scissors

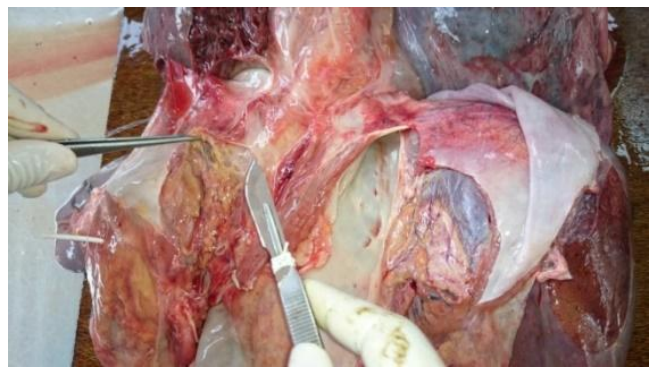

Fig-25: The author (AS) hunting for the left adrenal gland; while the right one has been exposed

The next organs to examine are the kidneys. The dissection is performed around the lateral/convex border of the kidneys simultaneously freeing it from perinephric fat [2]. Care must be taken by the prosector to not to injure the spleen while dissecting the left kidney. As the kidneys are separated from the conglomerate, the ureters must be inspected before completely detaching the kidneys. The kidneys need to be dissected for further examination. Cortical cysts are not uncommon and if not dissected carefully can lead to unexpected showers right on the face of the prosector and perhaps the eager on looking residents/students!! The kidney needs to be held in the non-dominant hand of the prosector with the concave border inwards and a sponge can be used for holding the organ firm. It is cut lengthwise/longitudinally using a brain knife (long bladed knife) from the convex border towards the hilum. A single sliding (proximally directed) stroke 
should be done using the knife [3]. The cortical and medullary areas (Fig. 26) can be easily assessed now (especially the boundaries). Pelvices can also be inspected. Width of the cortex as well as the clarity of the corticomedullary junctions must be examined [4]. Now the kidney while continued to be held in the nondominant hand (preferably with sponge), needs to be inspected further by stripping off the capsule. From the margin of incision at the convex border, a toothed forceps is used to grasp the free end of the capsule. It is stripped back slowly till the entire subcapsular surface is revealed. The adherence of the capsule as well as the colour changes of the subcapsular surface can be noted. Once the kidneys are removed the remaining loose adipose and connective tissues are severed. Periodically the wooden board and dissection area/field has to be cleared off the tissue debri and fluids by using running water. The prosector will miss important findings if the dissection is done in a messy field and most importantly like any surgical procedure even a post-mortem examination should be done aesthetically.

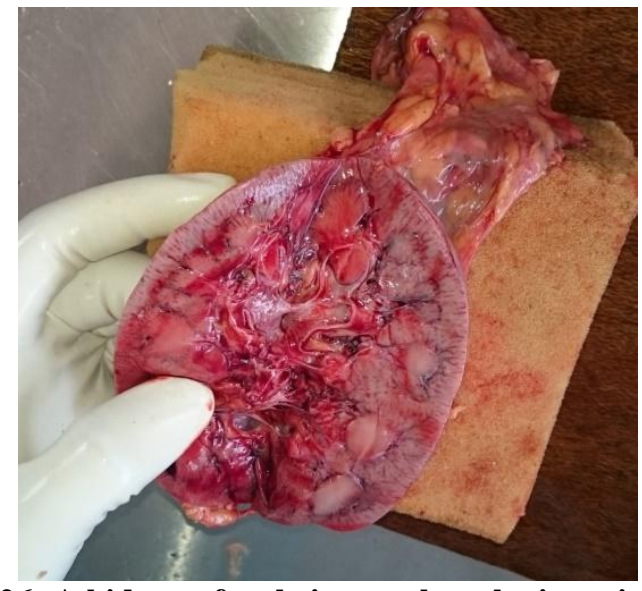

Fig-26: A kidney after being cut lengthwise using the brain knife

Spleen is next removed by slicing through its pedicle. One single section is made through its longest diameter and if required several incisions can be made parallel to this incision $[3,6]$. Pancreas is the organ examined next. Most of the literature is not indicating removal of pancreas from the entire visceral mass [2, 6]. In the experience of the authors this is logical and practical. Head of the pancreas will be within the loop of the duodenum. A longitudinal section is made from the head to the tail end using the scalpel. Several parallel sagittal slices can be made to examine the parenchyma when required (Fig. 27). Sectioning the pancreas crosswise [3] can help the prosector to assess the patency of the pancreatic duct. Attention is then given to examination of the oesophagus, stomach and duodenum. The surface of stomach is washed with running water and is wiped with a sponge. It is then opened by producing a hole along the greater curvature [4] using a scalpel approximately four cms proximal [2] to the pylorus. A container is held at mouth of this opening and the contents in the stomach are allowed to be drained. Then the ' $\mathrm{C}$ ' loop of duodenum is opened from its distal end (the jejunum was resected from this end during evisceration). The blunt end of the scissors is introduced and the loop is opened up and the incision is continued along the greater curvature of the stomach and further continued if necessary into the oesophagus upwards. This can aid demonstration of lower oesphageal pathology such as varices [2]. Any remaining contents in the stomach (semi-solid or solid materials etc) can be scraped out to the container. At times the lesser and greater curvatures of the stomach are avoided for dissection if they are suspected to be sites of pathology [2]. Hence the line of incision of the stomach depends on the prosector [6]. Alternatively, instead of the in situ dissection, the stomach ends (both cardiac and pyloric) can be tied and resected to open it under a hooded sink to avoid the unpleasant odour of the gastric contents [3]. The patency of the biliary system can be assessed by squeezing the gallbladder and checking for bile flow from the ampulla of Vater in the duodenum (Fig. 28).

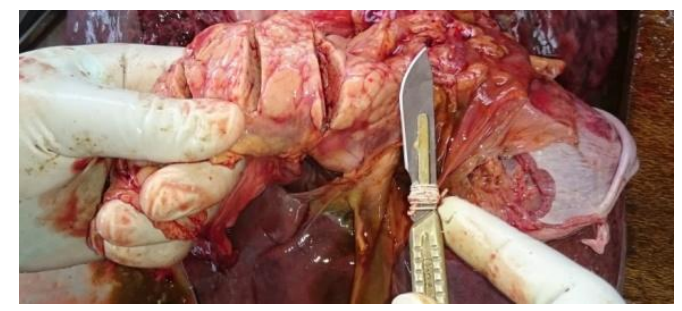

Fig-27: Pancreas after serial sectioning

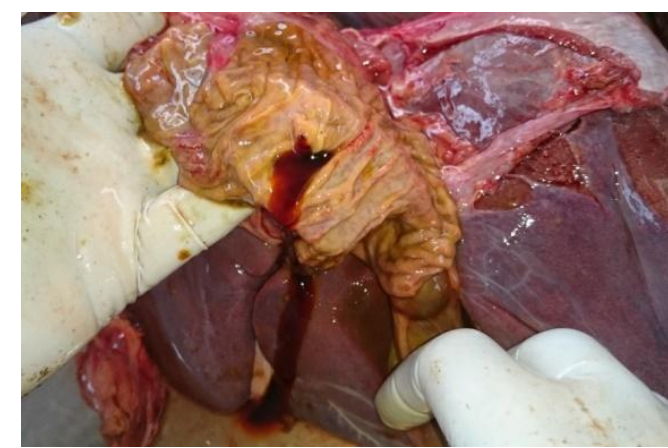

Fig-28: The author (AS) demonstrating patency of the biliary system

The stomach, lower portion of the oesophagus and the duodenum along with adjacent tissues are resected and removed from the dissection field. Liver is separated from the visceral mass and is examined next. A series of parallel vertical or horizontal cuts are made across the parenchyma approximately two $\mathrm{cms}$ apart [2]. A brain knife is used for dissecting the liver (Fig. 29). Finally, the prosector diverts his attention to the thoracic organs. Other than for the thoracic block, all the remaining organs and tissues which had been examined are removed from the dissection field. The thoracic block is aligned in such a way that the neck and adjacent structures are placed proximal to the prosector (closer to the prosector in immediate vicinity). 


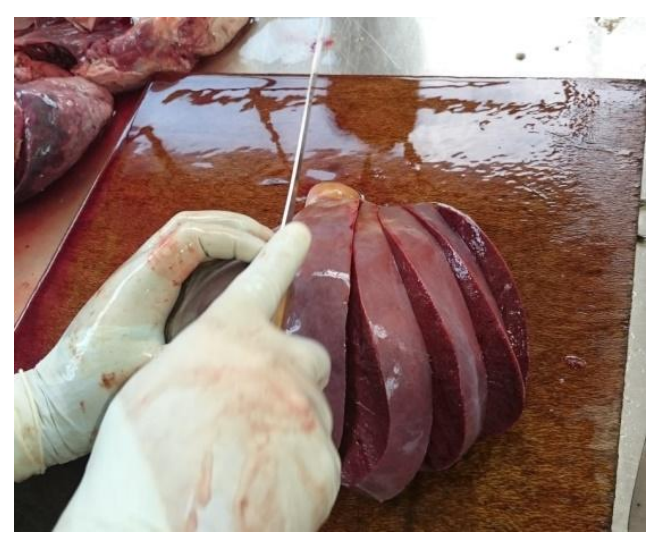

Fig-29: Serial sectioning of the liver

Depending on the importance of neck dissection, removal of the brain can be done prior to the examination of the neck structures. This allows drainage of blood from the head in order to avoid artefactual haemorrhages during neck dissection [2]. Neck examination already commences at the evisceration stage. Platysma, sternocleidomastoid and the suprahyoid as well as the infrahyoid muscles are inspected for any significant findings during the evisceration of neck. The thyroid gland is also sectioned in situ for examination. The remaining examination can be done while inspecting the thoracic block. The glottis is then inspected for any obstructions whereas the hyoid and thyroid horns are palpated for fractures [4]. The oesophagus is opened with a scissors. The hyoid bone and thyroid cartilage are examined for areas of haemorrhage and or fractures. Hyoid bone is then separated from the thyroid cartilage by cutting through the ligaments in between them using a brain knife [7]. The tongue is held in the non-dominant hand and due to the weight of the thoracic block acting downwards, the tissues between their horns will be stretched making a clear demarcation to severe the tissues. The tissues and skeletal muscles covering the hyoid bone, thyroid cartilage and cricoid cartilage can be stripped off for proper examination. The thoroughness of the examination depends on the circumstances of each case. The tongue is sectioned serially to detect any deepseated haemorrhages or contusions [4]. The neck examination concludes by opening the trachea.

Now what remains in the thoracic pluck are the lungs and the heart. The neck organs are then resected out leaving the lungs with heart to be examined subsequently. Appropriate precautions (mask and spectacles) are necessary to be used if the lungs contain active tuberculous lesions or any hazardous infections [3]. The examination of airways has to be completed prior to proper examination of the lungs. The right and left bronchi are opened using scissors and this is continued into the lobar bronchi, segmental bronchi and finally bronchioles (Fig. 30). For the distal air passages smaller scissors can be used. Thereby an impression of the caliber of the airways as well as the parenchymal texture of the lungs can be obtained [2]. Now the lungs are separated from the thoracic pluck using a brain knife passed through the hilum of the lungs [4]. If necessary, the assistant can be instructed to provide necessary traction while the lungs are being resected. While hilum is being cut, the prosector must be vigilant to observe for any signs of embolism within the pulmonary arteries. It is not necessary to open the right side of the heart along with the pulmonary trunk as any large embolus will be visible even in sequential examination of lungs followed by the heart [4]. In order to examine the entire parenchyma of the lungs, a horizontal slice through the lung is necessary with a brain knife [2]. The lung is laid flat on the wooden board with the medial side downwards (region of hilum). A sponge is then used to press down on the outer surface of the lung to prevent the organ from slipping as well as to protect the non-dominant hand. The lung is placed on the dissection board such that the base is proximal and apex is distal. The knife is held parallel to the dissection board and a horizontal slice along the sagittal plane (directed proximally) is made from the apex to base. The cut surfaces can be examined properly (Fig. 31). Sometimes it is advisable to use a dry sponge and not running water to examine lungs [6].

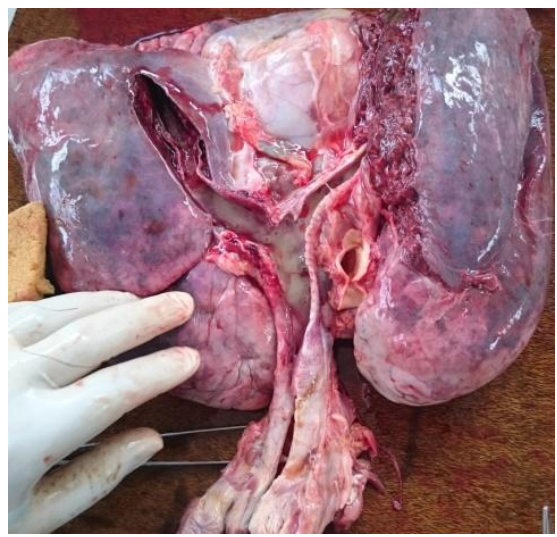

Fig-30: Examination of the air passages

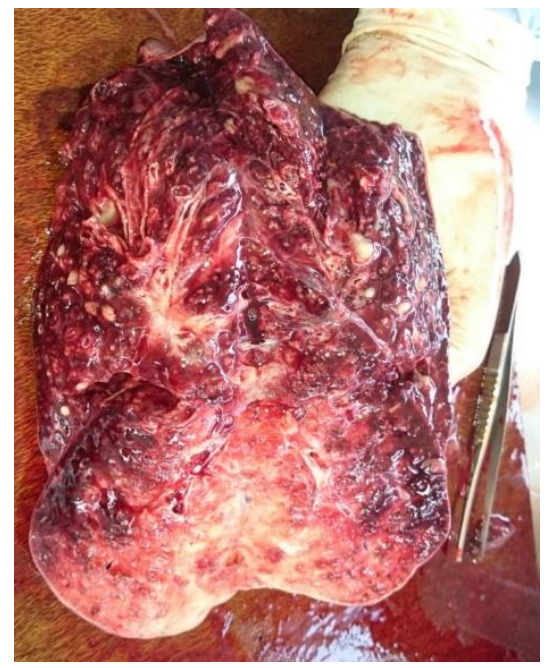

Fig-31: Lung parenchyma showing exudation of pus after dissection 
The only remnant of the visceral conglomerate is the heart. Cardiac diseases are one of the most frequently seen pathology during medico-legal autopsies [2]. The examination of heart is one of the most important features and must be done carefully. There are many techniques of examining a heart during autopsy but it is necessary to maintain a balance between obtaining maximum information and minimizing disruption of structure of the heart so as to properly demonstrate the findings $[2,4]$. The two basic methods of heart dissection are as follows: opening along the path of blood flow and ventricular slicing. While comparing these two methods; ventricular slicing is advantageous for precisely locating ischaemic changes. However, the huge drawback is that the organ continuity cannot be maintained thereby forcing the prosectors to open up heart along the path of the blood flow (more commonly practiced technique). Whichever way the heart is dissected, the blood vessels (coronaries) must be examined using one of the two methods. They are transverse sectioning or longitudinal opening of the coronary vessels. Transverse sectioning is preferred as it allows the degree of stenosis to be assessed accurately and is also less likely to dislodge a thrombus [2, 4]. In ventricular slicing technique it is a must to examine the arteries prior to dissection of the heart. In the opening heart method, it is advantageous to examine the vessels after dissection. This is because the vessels are easier to be identified and any ischaemic pathology that had been noted during dissection can be correlated with the inadequate vascular supply [2].

The opening heart method and transverse sectioning technique of examination of the coronary vessels will be discussed here since it is the common as well as the practical routine pattern followed by most of the prosectors [4]. The pericardium is externally inspected and then using forceps (toothed) and scissors it is opened wide. The heart is delivered through the incision, held in the anatomical position and external examination is completed (excluding taking weight of the organ - done only after complete dissection and examination). Either a scissors (medium size) or a brain knife (long knife) or a combination of the both can be used for dissecting / opening the heart in the direction of the flow of blood [2]. The vena cava openings are connected first [3]. Scissors is used to cut through the opening of the inferior vena cava and the incision is continued till the opening of the superior vena cava. Thereby the right atrium is opened. Then a second incision is made until the apex of the right auricle. The interior of the atrium, auricle and the tricuspid valve is inspected. For opening the right ventricle either the long knife or the scissors can be used. The incision can be made through the tricuspid valve and continued till the apex of the right ventricle keeping as close as possible to the posterior aspect of the interventricular septum. The entire right side of the heart is opened. The chambers, valves and walls can be examined now after washing properly.
The next incision is from the apex of the right ventricle through the opening of the pulmonary artery keeping as close as possible to the anterior aspect of the interventricular septum. The cusps of the valves must be cut in between and not through them. In the experience of the authors, this can be achieved by inserting the scissors along the path intended to cut and letting the heart rest down on the cutting surface of the scissors. Simultaneously the heart is supported by the non-dominant hand. This lets the incision to be done exactly in between the valves. Occasionally junior residents can use a forceps as a guide for opening up along the pulmonary artery. The valves can be examined by pouring water. The prosector can follow a similar procedure on the left side of the heart. The four pulmonary veins can be joined to open up the left atrium. An accessory incision can be made to examine the left auricle. The mitral valve can be examined. Considering the thickness of the left ventricular wall it is advisable to use a long knife for opening up this chamber of the heart. The heart is placed on the wooden board, the long knife is inserted and the apex is pierced. Incision is made along the left lateral margin of the ventricle by swiping outwards. The non-cutting hand is placed on the heart pressing it down as the outer margin is severed. The walls, valves and chambers are examined after washing properly. The opening of the heart will not be concluded without opening the aorta. The scissors are inserted into the aorta from the severed left ventricle chamber. The scissors are lifted thereby letting the heart rest on the cutting surface. Then the aorta is opened. The authors have found this method to be beneficial since the incision occurs exactly between the cusps of aortic valves instead of cutting through them. The valves are examined by pouring water and the openings of coronary arteries are inspected. It is important to identify the origin of the coronary vessels since anatomical variations of the ostia or the atheromatous changes around them are occasionally seen. The heart can be weighed at this point.

For transverse sectioning of the vessels, a sharp fresh scalpel blade should be used. The coronaries are sectioned at frequent intervals of not more than three $\mathrm{mm}$. Whenever an atheroma or thombus is discovered, the incisions can be put more closely together if possible [2]. The grip on the heart with the non-dominant hand must be firm and extreme care must be taken to not to lead to personal injuries. The left coronary artery can be transected at its common trunk. The anterior descending branch is then serially sectioned up to almost the apex. The left circumflex branch is also transected till it becomes intramuscular. Then the origin of the right coronary artery is identified (from its ostia) and is opened. It is followed laterally till it becomes the posterior descending branch (in case of dominance of right coronary artery). The myocardium can be studied more closely especially when the location of a narrowed coronary vessel has to be 
compared with the ischemic changes of the surrounding myocardium. The intramural or sandwich cut through the entire thickness of the left ventricle is a useful method [4]. Even histological blocks can be taken. The heart is placed on the dissection board with the opened ventricle chamber facing upwards. Equidistant slicing is done using the brain knife through the myocardium exposing the areas of infarct (if any).

The last major organ to be examined is the brain. External examination of the cerebrum, cerebellum and the brain stem is done. The examination is incomplete if the blood supply at the base of the brain is not inspected. From this point, it is important for the prosector to decide whether or not to fix the brain for further examination $[2,4,6]$. Weight of the brain has to be taken prior to fixation. Fresh brain is very soft (especially in cases of longer time since death) and hence must be handled with at most care. Fixation of brain provides a far better examination but the time delay for the process of fixation will not be acceptable by some prosectors. Unless the cause of death is only pertaining to brain that requires a proper examination; it is not worth the wait to dissect brain after fixation. The dissection is essentially the same whether brain is fresh or fixed. The brain knife should be sharp and must be dipped in water before each section is made. The brain is placed on the wooden dissection board with its convexity upwards and frontal lobes directed away from the prosector. Sectioning using the brain knife should be done with a continuous stroke to assure a uniform and smooth surface. The cerebral hemispheres are gently parted with the left hand (non-dominant hand) and the brain knife is inserted into the longitudinal sulcus. The knife is placed parallel to the surface and along the region of corpus callosum first the right, followed by the left, the hemispheres are sliced with horizontal sections directed outwards [6]. The section is not a complete one on both sides enabling the sectioned brain to be opened like pages of a notebook. The brain tissues are still attached along lateral edges on both sides. After examining the white substance of the opened sections, the lateral ventricles are then opened along their length ( $\mathrm{C}$ shaped) by cutting into the white substance using a scalpel. The horns of the lateral ventricles are examined by following the choroid plexus.

The scalpel is passed through the interventricular foramen of Monro, directed upwards and anteriorly and is sliced through the fornices and corpus callosum. Since detached anteriorly, the corpus callosum and fornices are bent back exposing the third ventricle. The sylvian aqueduct can be examined using a probe. The third ventricle, caudate nucleus and thalamus are examined after cutting off the commissural fibres (corpus callosum). Using the brain knife another incision is made parallel to the incision made for removing cerebral hemispheres [6]. In the experience of the authors there is no harm in directing the incision slightly downwards for better appreciation of the structures beneath. On both sides the incision begins off from the lateral walls of the lateral ventricles about one $\mathrm{cm}$ beneath the previous incision. This section is also not a complete one, whereby the brain tissues are still remaining attached at the lateral peripheral cortical regions. The basal ganglions, internal capsule and external capsule can be now examined. Further, parallel sections beneath are indicated only for examination of deeper tissues. By now each section can be treated like a flap which can be turned about its cortical attachment to expose the cut surface beneath it (Fig. 32).

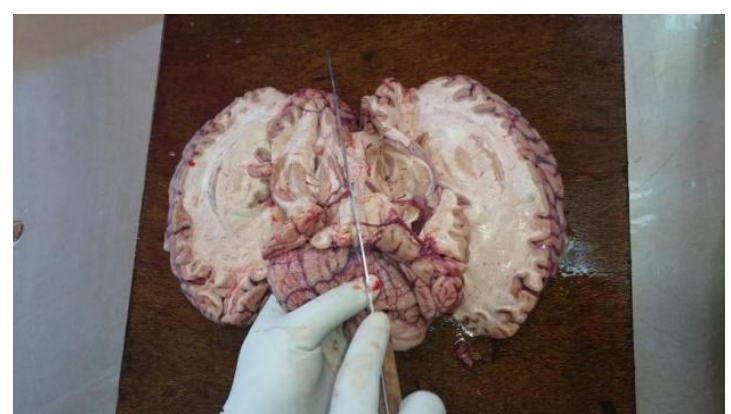

Fig-32: Notebook dissection of the brain

The brain stem and cerebellum is supposed to be examined subsequently towards the end stages of brain dissection [6]. Though literature [2, 4, 6] supports separation of brain stem and cerebellum from cerebral cortex prior to their dissection and examination; the author feels that these structures can be examined in continuity with the cerebral cortex. The only citation about examining the structures in continuity is when there is a tumor/mass extending to all the abovementioned structures [2]. Whether attached or examined separately the dissection techniques of these structures essentially remains the same. The advantage of examining the entire brain in continuity is that the anatomical orientation is not disrupted. After examination of the deeper structures of cerebral cortex such as the internal and or external capsules; a midline/vertical incision is put using the brain knife at the level of the pons and vermis portion of the cerebellum (not too deep) [4]. This exposes the floor of the fourth ventricle as well as the dentate nuclei and the interior portion of the cerebellum. The palm of the noncutting hand is placed under the brain directly below the brain stem area. The hand is then lifted extending and exposing the brain stem properly for dissection. Using a fresh scalpel, the entire brain stem is sliced at five $\mathrm{mm}$ intervals for proper examination of any lesions [2]. The lobes of the cerebellum are dissected with the brain knife by slicing across a horizontal plane passing across the dentate nucleus.

Last but not the least, examination of the genitalia should not be forgotten. External examination can be done along with general examination of the body. Internal examination is not done routinely in case 
of males but almost always done in case of females. The decision remains with the prosector. In case of males, an incision is made on the inner surface of the abdominal wall in the region of the inguinal canal. Two fingers of the non-dominant hand (left hand) is introduced through the inguinal canal into the scrotal sac whereas the right hand of the prosector locates the testis of that side and inverts the scrotum pushing out the testis and epididymis into the left hand. The testis and epididymis is delivered by cutting off from the attachments. The same procedure is done on the other side too. Each testis with epididymis is held in the nondominant/left hand and is cut lengthwise/longitudinally with a scalpel (one section). The organ must be held firm in the left hand to prevent slipping. While dissection is being done, the organ must be directed away from face of the prosector or onlookers to prevent splash of fluids. In case of women, it is rarely necessary to remove the entire genital tract unless indicated. For routine examination; the uterus (including cervix), ovaries, fallopian tubes and the upper vagina are removed together [2]. All the organs are opened along their front (anterior) portion [6]. The uterus is opened by a midline longitudinal incision [2] using a scalpel or brain knife extending from the vaginal cuff through the cervix till a point $0.5 \mathrm{~cm}$ [6] below the fundus. The incision should be deep enough until the endometrium is exposed. Often a metal probe inserted through the external cervical os can be used as a guide by beginners for assessing the depth of this incision. This way the endometrium, myometrium and cervix all can be inspected. Though literature also mentions an alternate method of using scissors to open the uterus; the authors have found it to be cumbersome and impractical. In almost all the cases the cervical canal will be closed and too narrow to allow the passage of lower blade of scissors. From below the fundus the incisions can be extended to both sides opening the tubes [6]. The patency of the tubes can be assessed if required using probes prior to dissection. The ovaries after being positioned (using the left hand on to the dissection board) are dissected along their longest diameters (sagittal section) using a scalpel.

\section{CONCLUSION}

All the procedures done so far should be done with the cleanliness that approaches a surgical operation. Sponges and water must be used frequently to clean and dry the body cavities. All the dissected viscera must be washed in water and must be drained off excess fluids. Soiling with faecal matter should be avoided. The viscera must be preferably wrapped in cotton or guaze cloth materials before being placed in the trunk. The pelvic cavities and the base of the cranial cavity must be tightly packed with cotton and guaze to prevent leakage of fluids [6]. The team involved in the autopsy procedures must always remember that the body on the table was once housed by a living human being. The respect and attitude to be given to the cadaver should be the same way as how one would prefer him/herself to be respected by others.

The incisions on the body should be stitched using a moderately small (to avoid disfigurement and leakage) needle (curved or straight) and cotton cord/twine. The entire body after suturing has to be washed well, dried and dressed in attire as how the deceased would have preferred if $\mathrm{s} / \mathrm{he}$ was alive (standard procedures in a funeral home). This can be discussed with the relatives or the next of kin. Once the body is prepared, it can be handed over to the police who will transfer the same to the relatives for funeral. In case of unclaimed dead bodies, the police themselves can dispose the cadaver as per the rules pertaining to that particular State.

\section{REFERENCES}

1. Royal College of Pathologists. (1993). Guidelines for post mortem reports. Royal College of Pathologists. London.

2. Sheaff, M.T, Hopster D.J. (2009). Post Mortem Technique Handbook. $2^{\text {nd }}$ ed. (First Indian Reprint). Springer (India) Private limited.

3. Baker, R.D. (1967). Postmortem Examination Specific Methods and Procedures. $1^{\text {st }}$ ed. W.B. Saunders Company, Philadelphia \& London.

4. Saukko, P., Knight, B. (2016). The Forensic Autopsy In: Knight's Forensic Pathology. $4^{\text {th }}$ ed. Arnold Publishers, London.

5. Pillay. V.V. (2011). Medicolegal Autopsy In: Textbook of Forensic Medicine \& Toxicology. $16^{\text {th }}$ ed. Paras Medical Publisher, Hyderabad.

6. Saphir, O. (1958). Autopsy Diagnosis and Technic. $4^{\text {th }}$ ed. Cassell and Company Limited, U.S.A.

7. Dolinak, D., Matshes, E., Lew, E. (2005). Forensic Pathology Principles and Practice. $1^{\text {st }}$ ed. Elsevier Academic Press, U.S.A. 